This item was submitted to Loughborough's Research Repository by the author.

Items in Figshare are protected by copyright, with all rights reserved, unless otherwise indicated.

\title{
Sink or swim: adversity- and growth-related experiences in Olympic swimming champions
}

\section{PLEASE CITE THE PUBLISHED VERSION}

http://dx.doi.org/10.1016/j.psychsport.2014.08.004

\section{PUBLISHER}

(C) Elsevier Ltd.

\section{VERSION}

AM (Accepted Manuscript)

\section{PUBLISHER STATEMENT}

This work is made available according to the conditions of the Creative Commons Attribution-NonCommercialNoDerivatives 4.0 International (CC BY-NC-ND 4.0) licence. Full details of this licence are available at: https://creativecommons.org/licenses/by-nc-nd/4.0/

\section{LICENCE}

CC BY-NC-ND 4.0

\section{REPOSITORY RECORD}

Howells, Karen L., and David Fletcher. 2019. "Sink or Swim: Adversity- and Growth-related Experiences in Olympic Swimming Champions”. figshare. https://hdl.handle.net/2134/20955. 
1

2

3

4

5

6

7

8

9

10

11

12

13

14

15

16

17

18

19

20

21

22

23

24

25

26

27

28

0
Sink or Swim: Adversity- and Growth-Related

Experiences in Olympic Swimming Champions

Karen Howells and David Fletcher

Loughborough University, United Kingdom

12

3

14

5

6

7

8

9

Author Note

1

Karen Howells and David Fletcher, School of Sport, Exercise and Health Sciences,

Loughborough University, United Kingdom.

We acknowledge Brett Smith for suggesting readings useful for analyzing the data. Correspondence concerning this article should be addressed to Karen Howells, School of

5 Sport, Exercise and Health Sciences, Loughborough University, Epinal Way, Loughborough,

6 Leicestershire LE11 3TU, United Kingdom. Voice: 4415-0922-8450. E-mail:

27 K.Howells@lboro.ac.uk 
Abstract

30 Previous research suggests that adversarial growth is a real and constructive phenomenon that

31 occurs in athletes who compete at the highest level of sport. In this study, however, we adopt a

32 critical stance on the veridicality of growth by exploring Olympic swimmers' experience of constructive and illusory growth. Semi-structured interviews, complemented by timelining, were undertaken with four international swimmers (two male and two female) who were aged between

3517 and 27 years at their first participation at an Olympic Games and who had experienced a

36 number of significant adversities. The interviews and timelines were analyzed using

37 interpretative phenomenological analysis. Despite the inherently negative aspects of adversity, it was evident from the swimmers' interpretations that they also perceived positive consequences of their experiences. Analysis revealed that some of these positive outcomes were indicative of

40 illusory aspects of growth (e.g., seeking meaning, cognitive manipulations), while other positive

41 outcomes were more indicative of constructive aspects of growth (e.g., finding meaning,

42 cognitive processing). Prior to growth occurring all of the participants used denial as a short-term

43 palliative coping strategy. It appears that earlier phases of the growth process were characterized

44 by more illusory aspects of growth, whereas when the temporal proximity from the adversity

45 increased and the swimmers accepted their adversities, more constructive aspects of growth are 46 apparent. 
Adversarial Growth in Olympic Swimmers: Constructive Reality or Illusory Self-Deception? A growing body of research has shown that individuals can positively change following adversity to the extent that they report development beyond their pre-trauma functioning (see, for a review, Linley \& Joseph, 2004). This growth typically involves an increased appreciation for life, more meaningful relationships, an increased sense of personal strength, a change in priorities, and a richer existential and spiritual awareness (Tedeschi \& Calhoun, 2004). Various terms have been used to conceptualize growth including posttraumatic growth (PTG; Tedeschi \& Calhoun, 1996), stress-related growth (SRG; Park, Cohen, \& Murch, 1996), and adversarial growth (Linley \& Joseph, 2004). Several theoretical explanations of growth have been proposed (viz., Joseph \& Linley, 2006; Zoellner \& Maercker, 2006a) including a functional descriptive model (FDM) of PTG (Calhoun, Cann, \& Tedeschi, 2010; Calhoun \& Tedeschi, 1998; Tedeschi \& Calhoun, 1995, 2004), an organismic valuing theory (OVT) of growth through adversity (Joseph \& Linley, 2005), and an affective-cognitive processing model (ACPM) of PTG (Joseph, Murphy, \& Regel 2012). These models posit that growth arises out of a person's struggle to deal with the shattered self (cf. Janoff-Bulman, 1992) that occurs as a result of a traumatic experience. This involves interaction between a variety of person and situational variables, central to which is an individual's cognitive processing, that leads to the experience of constructive growth.

In the study reported in this paper we focus on adversarial growth in elite sport.

Adversarial growth has been conceived as the changes that occur through the process of struggling with adversity that propel an individual to a higher level of functioning than that which existed prior to the event (Linley \& Joseph, 2004). Howells and Fletcher (2015) recently argued that sport performers who compete at the highest level typically experience adversities and potential for growth during their careers (cf. Sarkar, Fletcher, \& Brown, 2015; Tamminen, Holt, \& Neely, 2013). Elite athletes encounter a range of stressors originating from personal, organizational, and competitive sources (Fletcher, Hanton, \& Mellalieu, 2006; Sarkar \& Fletcher, 2014) and it is an athlete's subjective evaluation or appraisal of such demands that determines their severity (Lazarus, 1966, 1999). As Morris, Shakespeare-Finch, Rieck, and Newbury (2005) remarked, "the effect that an event has on the individual is ultimately subjective, as it is the 
individual's perceptions that allow for the event to be comprehended as traumatic” (p. 576). For elite athletes, who typically have high levels of athletic identity, stressors that have the potential to disrupt self-identity schema are often appraised as threatening due to heighten sensitivity (cf. Brewer, 1993; Brewer, Van Raalte, \& Linder, 1993). As Brewer (1993) observed, a severely sprained ankle is more likely to be evaluated as a major life disruption by an individual with high athletic identity than by an individual with low athletic identity. Some of the most potentially traumatic adversities in sport include sexual harassment or abuse (Fasting, Brackenridge, \& Walseth, 2002), depression (Mummery, 2005), emotional abuse or bullying (Stirling \& Kerr, 2008), eating disorders (Papathomas \& Lavallee, 2010), and injury (Powell \& Barber-Foss, 2000).

Sport psychology researchers have explored the perceived benefits (Wadey, Evans, Evans, \& Mitchell, 2011), PTG (Crawford, Gayman, \& Tracey 2014; Day, 2013; Day \& Wadey, 2016; McDonough, Sabiston, \& Ullrich-French, 2011; Sabiston, McDonough, \& Crocker, 2007), and SRG (Galli \& Reel, 2012a; Salim, Wadey, \& Diss, 2015, in press; Wadey, Clark, Podlog, \& McCullough, 2013) experienced by recreational and competitive participants. Pertinent to the present study is that several researchers have specifically studied the notion of adversarial growth in athletes competing at non-elite (Galli \& Reel, 2012b) and elite (i.e., Howells \& Fletcher, 2015; Sarkar, Fletcher, \& Brown, 2015; Tamminen, Holt, \& Neely, 2013) levels. In terms of the elite sport research, Tamminen et al. (2013) found that as some international female athletes sought and found meaning in their experiences of adversity, they identified opportunities for growth associated with social support and the role of sport in their lives. Following interviews with Olympic champions, Sarkar et al. (2015) reported that the adversity-related experiences of trauma, motivation, and learning appear to play an important role in champions’ psychological and performance development. In their study of adversarial growth in elite swimming, Howells and Fletcher (2015) found that Olympic champion swimmers who perceived their adversityrelated experiences to be traumatic, initially adopted maladaptive coping strategies before seeking meaning in their experiences and turning to others for support. These strategies facilitated growth which was identifiable through superior performance, enhanced relationships, spiritual awareness, 
105

106

107

and prosocial behavior. Collectively, the findings from these studies suggest that adversarial growth is a real and constructive phenomenon that occurs in athletes who compete at the highest level of sport (cf. Crawford et al., 2014; Day, 2013; Wadey et al., 2013).

Although the notion of adversarial growth has received growing support in the sport and broader psychology literature, some scholars have questioned the veridicality of growth experiences (e.g., Maercker \& Zoellner; 2004; Park, 2004; Zoellner \& Maercker, 2006a; Wortman, 2004). In 2004, Maercker and Zoellner were unconvinced by some accounts and evidence of PTG and suggested that self-deception was occurring in an attempt to convince oneself of positive outcomes. They termed this self-deception as illusory growth potentially associated with denial, avoidance, wishful thinking, self-consolidation, or palliation, and they proposed the Janus-faced model of self-perceived PTG (Maercker \& Zoellner, 2004; Zoellner \& Maercker, 2006a). This model recognizes and incorporates the constructive perspective of growth evident in other models of growth, such as the FDM of PTG (Tedeschi \& Calhoun, 2004); however, what makes this model different from others is the inclusion of illusory growth. Drawing on Taylor and colleagues’ (Taylor, 1983; Taylor \& Armor, 1996; Taylor, Kemeny, Reed, Bower, \& Gruenewald, 2000) research on adjustment to threatening events, Maercker and Zoellner (2004) argued that people often respond to threatening events with mildly distorted positive perceptions of themselves, exaggerated sense of personal control, and unrealistic optimism (see also Zoellner \& Maercker, 2006a). As such, illusory growth is associated with cognitive avoidance strategies as part of a coping process which will likely, in the longer term, have deleterious effects on adjustment. If in the shorter term, however, illusory growth is accompanied by deliberate thinking about the trauma and active coping efforts, it may serve a palliative function. Evidence supporting a two-component model of growth has been reported in victims of stressful life events (McFarland \& Alvaro, 2000), parents of children treated for leukaemia (Best, Streisand, Catania, \& Kazak, 2001), cancer patients (Sumalla, Ochoa, \& Blanco, 2009; Widows, Jacobsen, Booth-Jones, \& Fields, 2005), and motor vehicle accident survivors (Zoellner, Rabe, Karl, \& Maercker, 2008, 2011). Given the aforementioned theoretical and empirical advances in illusory growth, it is 
133 surprising that no sport psychology researchers have have explicitly focused on or provided

134 empirical data relating to its occurrence in athletes. Some have questioned whether growth

135 actually occurs (Wadey et al., 2013) and acknowledged the possibility of the illusion of growth as

136 a coping strategy (Tamminen et al., 2013), and Howells and Fletcher (2015) concluded their

137 recent study in this area with an oblique reference to the potential for illusory growth: "The

138 Olympic champion swimmers studied in [our] research ultimately thrived in the face of adversity

139 by adopting transitional-related strategies that helped them not only overcome their experiences

140 but also, they believed [italics added], flourish as both sport performers and human beings” (p.

141 46). In the present study, we extend Howells and Fletcher's research by adopting a critical stance

142 on the veridicality of growth and by exploring Olympic swimmers' experiences of constructive

143 and illusory growth during their lives. Such an approach offers a more complete theoretical

144 understanding of, and empirical insight into, sport performers' experiences of adversarial growth

145 across their lifespan.

\section{Methods}

147 Design

148 The self-deceptive nature of illusory growth presents a significant challenge for

149 researchers in this area because study participants are - by definition - unable to ascertain illusory

150 growth when it is occurring, and typically for some time afterwards. As Joseph et al. (2012)

151 remarked, "it may be that perceptions of growth are at times illusory.... As such, researchers

152 need to be wary of taking reports of growth at face value” (p. 319). Consequently, others are

153 typically required to infer that self-reported growth may be deceptive. In this study, we

154 interpreted illusory growth via the identification of indicators of illusory growth (e.g., optimism;

155 Zoellner et al., 2008, 2011) and of an absence of constructive growth (e.g., absence of action;

156 Hobfoll et al., 2007) when a participant had claimed to have grown from adversity. Across both

157 of these approaches, we engaged the double hermeneutic involving we, the researchers,

158 interpreting the participants' interpretations of their own experiences (cf. Giddens, 1984; Mottier, 159 2005).

160 Given the salience of others' interpretations in the identification of illusory growth, this 
161

162

163

164

165

166

167

168

169

170

171

172

173

174

175

176

177

178

179

180

181

182

183

184

185

186

187

188

study's design was guided by the principles of interpretative phenomenological analysis (IPA)

which is a qualitative methodology that involves investigating the sense that individuals make of their experiences through a process of engaging with their reflections (Smith, Flowers, \& Larkin, 2009). It is useful for better understanding psychosocial processes, particularly as they unfold over time (Brocki \& Wearden, 2006). Thus, IPA was deemed an appropriate methodology to explore the sense making and personal meaning in individuals’ self-reported growth (cf. McDonough et al., 2011; Tamminen et al., 2013) and an ideal method to interpret the occurrence of illusory growth.

\section{Researchers}

In their discussion about the principles of IPA, Larkin, Watts, and Clifton (2006) emphasized that "we must identify the researcher as an inclusive part of the world that they are describing” (p. 107). As the analysis involves researchers' interpretations of participants' interpretations of their reported experiences it is possible that the findings are incongruent with participants' accounts. Accordingly, it is important that researchers disclose their own background, values, and assumptions. Both authors have a background and an interest in the sport of swimming and, therefore, have an understanding of the competitive swimming community, nomenclature, and culture. Our epistemological stance can be described as constructivist in nature and seeks to understand people's constructions of their lived experiences. It is consistent with an ontological positioning that is in-between realist and relativist in "that while experience is always a product of interpretation and therefore constructed . . . it is nevertheless 'real' to the person” (Willig, 2009, p. 13).

\section{Participants}

A purposeful sampling procedure was adopted because IPA seeks to capture and represent idiographic phenomena (Smith et al., 2009). IPA is used with broadly homogenous groups (Brocki \& Wearden, 2006) so inclusion criteria for participation in this study was that potential participants had competed in a swimming event at an Olympic Games and were, at the time of the data collection, over the age of 18 years. Following institutional ethical approval, potential participants were contacted via swimming coaches at a national swimming competition and 
189

190

191

192

194

195

196

197

198

199

200

201

202

203

204

205

206

207

208

209

210

211

212

213

214

215

216

through private messaging on social media (i.e., Twitter). Although the coaches were known to both authors, they did not have professional relationships or friendships with either author. Three swimmers were approached at the competition with their coaches' approval and two agreed to take part, six swimmers were approached via social media and two agreed to take part.

In accordance with the idiographic nature of IPA, this study comprised a sample of four participants; a size that is typical of other IPA studies (e.g., Caron, Bloom, Johnston, \& Sabiston, 2013). Two of the swimmers were male, Jon and Tim, and two of the swimmers were female, Kate and Zoe (all names are pseudonyms), their ages ranged from 17-27 years at the time of their Olympic participation. All of the swimmers had competed in least one Olympic Games, Jon, Tim, and Kate had retired in 2004, 2008, and 2012 respectively, and at the time of data collection, Zoe was planning to retire in 2016. The swimmers all reported significant adversities which had occurred either prior to, or during their competitive swimming careers including, but not restricted to, illness, injury, coach conflict, relationship breakdown, and performance slumps. The differences in the swimmers' gender and dates of retirement allowed identification of convergence and divergence which may arise in the sample (Smith et al., 2009).

\section{Data Collection}

Semi-structured interviews, complemented by timelining, lasting between 60 and 90 minutes, were conducted by the first author. At the start of each interview, the participant was asked to draw and then annotate a timeline of their experiences with a particular emphasis on their “life highs and lows”. Timelining, a form of graphic elicitation which records, extends, and deepens understanding of participants' past experiences, provided a temporal foundation for discussions that encouraged the participants’ recall (Sheridan, Chamberlain, \& Dupuis, 2011). The use of chronological accounts can provide a useful structure for interviews and facilitate "the process of entering the participant's world” (Smith et al., 2009, p. 82) which is an essential feature of IPA. Timelines were, therefore, valuable in this study for better understanding the relationships between adversities, trauma, and growth. The participants chose their own timeframe allowing them to focus on times when swimming and adversarial growth were salient in their lives. In addition to the timelining, the interviews were also informed by a schedule that 
217 contained questions and probes relating to adversity- and growth-related experiences. The

218 schedule acted as a guide for the interviewer and comprised four sections: introductory questions

219 relating to the role of swimming in the participants’ lives (e.g., “can you tell me what place

220 swimming had in your life in the build-up to your first selection for the Olympic Games?”),

221 questions relating to the participants' experiences of adversity (e.g., “can you tell me about any

222 event or period in your life that you found particularly difficult?”), questions regarding the

223 participants’ responses to adversity (e.g., "how did you react to [adversity]?”), and questions

224 relating to perceptions of change (e.g., “have your experiences changed you or your outlook?”).

225 Prompts and references back to the timeline were used to facilitate disclosure and discussion.

226 Importantly, similar to the procedure adopted by McDonough et al. (2011), the interviewer

227 avoided explicit terminology referring to growth per se (e.g., PTG, SRG) in an attempt to

228 circumvent “a tyranny of positive thinking” (Lechner \& Antoni, 2004, p. 39) whereby individuals

229 experience sociocultural expectations to report positive outcomes of adversity. The interviews

230 were recorded with audio equipment and then were manually transcribed by the first author.

\section{Data Analysis}

232 The data was analyzed on a case-by-case basis in accordance with Smith et al.'s (2009)

233 IPA six step process. This process began with the first author immersing herself in the original

234 data by listening to the interview recording, by scrutinizing the associated transcript, and by

235 reviewing the timeline (step one: reading and re-reading). Initial notes were then recorded in

236 respect of the descriptive, linguistic, and conceptual meanings of the participant's interpretations

237 of his or her experiences and how these aligned with the timeline and associated annotations (step

238 two: initial noting). In this study, this included noting the swimmer's descriptions of adversity-

239 related experiences, his or her narrative style (e.g., the use of first, second, and third person), the

240 location of the adversities on the timeline and how they were illustrated in comparison to other

241 experiences, and the perceived impact of the adversities. The next step in the analysis involved

242 the conversion of the initial notes into emergent themes (step three: developing emergent themes)

243 which required the first author's interpretation of the swimmer's experiences. For example, some

244 initial notes from step two related to the swimmer's search for meaning following adversity; 
245 however, in the third step of the analysis it became apparent that some instances were about

246 understanding why an event occurred whereas other instances involved appreciating the

247 significance of an event in the swimmer's lives. (We interpreted the former as being indicative of

248 illusory growth whereas the latter as being indicative of constructive growth).

249 The fourth step in the analysis involved using processes of abstraction to group similar

250 themes and polarization to differentiate between distinct and opposing themes (step four:

251 searching for connections across emergent themes). Similar themes relating to perceived positive

252 changes integrated into a preexisting schema (labelled as assimilation of a positive bias) and

253 expressions of hope for the future (labelled as developing a positive outlook) were grouped

254 together in a theme representing swimmers' manipulating their thoughts and interpretations with a

255 positive bias (labelled as cognitive manipulations). Opposing themes, such as perceived positive

256 changes indicative of a shattered and reformed schema (labelled as positive accommodation) and

257 a change in one’s identity (labelled as identity change), were grouped together in a theme

258 representing swimmers' reflections on their experiences and interpretations in a meaningful way

259 (labelled as cognitive processing). The penultimate step of the analysis involved repeating the

260 first four steps for each of the (three remaining) cases (step five: moving to the next case) and

261 then, in the final step, using an iterative approach the cases were considered together to identify

262 connections, patterns, and differences between the cases (step six: looking for patterns across

263 cases). This analytical process was reviewed by the second author and interpretations, apparent

264 inconsistencies, and alternative explanations were discussed. Any differences between the

265 authors' interpretations were resolved through dialogue, and themes were refined and re-labelled

266 accordingly.

\section{Research Quality}

To evaluate the quality of the research, Smith’s (2011) guidance for evaluating IPA was applied to the research process and product. This study has a clear focus on Olympic swimmers' experiences of constructive and illusory growth during their lives. Multiple data collection methods, involving semi-structured interviews, timelines, and follow-up e-mail questions, were used to strengthen the quality of the data. The rigor of this research has, in part, been evidenced 
273 by giving some indication of the prevalence for a theme and by providing extracts from at least

274 half of the participants. Sufficient space has been given to reporting illusory and constructive

275 growth to provide an in-depth and balanced portrayal of the participants' experiences. The results

276 go beyond description and involve presenting an interpretative commentary with each extract to

277 make sense of the participants and their experiences. An important aspect of this interpretative

278 process was the analysis of what the participants disclosed (and did not disclose) elsewhere in the

279 interview (cf. Smith 2004). This was significant for this study because to interpret illusory growth

280 we not only identified indicators of illusory growth but also an absence of constructive growth

281 when a participant had claimed to have grown from adversity. The analysis pointed to

282 convergence and divergence both within and between participants in terms of the extent to which the participants provided evidence for the veridicality of their growth experiences. In presenting the results, we have attempted to craft a carefully written narrative that provides the reader with a critical insight into the phenomena of growth as experienced by Olympic swimmers.

An important aspect of qualitative research quality is the notion of trustworthiness of the data analysis procedures (Lincoln \& Guba, 1985). A commonly used strategy to enhance trustworthiness is member-checking which is a "way of finding out whether the data analysis is congruent with the participants' experiences” (Curtin \& Fossey, 2007, p. 92) and has been used previously in IPA studies in sport psychology research (e.g., Hassell, Sabiston, \& Bloom, 2010; Levy, Polman, Nicholls, \& Marchant, 2009). In this study, member-checking began with sending a copy of the interview transcript to each of the corresponding participants and inviting him or her to comment on the accuracy of the content (Smith et al., 2009). Further to this and in line with recommended member-checking procedures (cf. Carlson, 2010; Creswell, 2009; Kornbluh, 2015), a copy of the manuscript was later (i.e., after the analysis of the data and the authors' interpretation of the findings) sent to the participants inviting them to comment on whether the they understood the interpretations and content (e.g., Does this make sense to you?) and whether the narrative accurately reflected their own lived experiences (e.g., Do you think that the interpretations and content accurately reflected your own experiences?). To facilitate 
301

302

303

from difficult experiences) and illusory growth (viz. deceiving oneself that one has positively

benefited from difficult experiences) were provided. It was emphasised as part of the instructions that if the participants didn’t understand anything or disagreed with anything, that they should seek clarification or express their concerns respectively. The manuscript was positively received by all four swimmers and there were no objections from any of the participants to either the interpretations or the content. Although some researchers have questioned the appropriateness of member-checking in qualitative interpretative research (see, e.g., Carlson, 2010; Larkin \& Thompson, 2012) given the primacy of authors' interpretations (as opposed to participants’ perspectives) in the research process, we deemed this procedure as a valuable and ethical part of enhancing trustworthiness in this particular study. Moreover, regardless of the aforementioned issues and procedures, the reader is encouraged to make their own interpretations - that is, engage a triple hermeneutic - of this research in relation to its trustworthiness (cf. Carlson, 2010; Creswell \& Miller, 2000) and the nature of adversarial growth in sport performers (Joseph et al., 2012; Zoellner \& Maercker, 2006a).

\section{Results}

The swimmers' experiences of growth were preceded by various adversities which were typically represented as lows or slumps on their timelines. The adversities included injury, illness, relationship difficulties, organizational stressors, and performance slumps and were contextualized within a performance narrative (cf. Douglas \& Carless, 2006) involving a real or perceived threat to the swimmers' identities. The swimmers' initial response to adversity was typically characterized by denial. Despite the inherently negative aspects of adversity, it was evident from the swimmers' interpretations that following their initial response they also perceived positive consequences of their experiences. Analysis revealed that some of these positive outcomes were indicative of illusory aspects of growth, while other positive outcomes were more indicative of constructive aspects of growth. The growth process typically began with self-deception, more illusory aspects of growth, and fewer constructive aspects. As the temporal proximity from the adversity increased and the swimmers accepted their experiences they typically reported more constructive aspects of growth and fewer illusory aspects. Although the 
themes are presented in a temporal fashion to portray this sequential process, it is important to note that the rate at which aspects of growth occurred varied both within and between the participants.

\section{Response to Adversity}

To protect themselves against the impact of negative emotions and distress, and to safeguard their identities as world-class athletes, the swimmers' initial response to adversity typically involved using denial as a short-term palliative coping strategy. Denial was characterized by a failure to acknowledge the impact of the adversity, suppression of the emotional consequences of the swimmers' experiences, an avoidance of reminders of the stressor[s], and a failure to disclose the details of the adversities to their social networks. Interestingly, although some of the swimmers explicitly recognized that they used denial, they still attempted to positively reinterpret their experiences by seeking out positive outcomes.

Jon explained that despite physically recovering from a life-threatening illness, he initially failed to acknowledge the impact that survival and recovery had on him. It was only when he met with a performance psychologist that he consciously recognized the enormity of his experience: “people had said it to me before but I didn’t necessarily feel it”. Tim was reflective about how he dealt with the consequences of a serious back injury and identified that denial was a strategy which allowed him to deal with the immediate aftermath:

There's a certain extent of . . . you reject it. And whether it's kind of alpha male machismo - 'I'll be fine' - sort of approach, which is inherently illogical, [or] whether it ... pushes you through, I’m not quite sure.

We interpreted a reticence to elaborate about certain experiences as evidence of suppression of the emotional consequences of the swimmers' experiences. When asked to recall her feelings towards swimming following her poor performance at the World Championships, Zoe stated: "I don’t know, I can’t remember, I probably hated it”. In an attempt to avoid discussing her six months abroad which she perceived as an adverse experience, she used the term "whatever" as a barrier to having to reflect on the experience: "I went out there and started in January 2009 . . [and] had six months of doing whatever”. In recalling the organizational stress that he endured 
357

358

359

360

361

362

363

364

365

366

367

368

369

370

371

372

373

374

375

376

377

378

379

380

381

382

383

384

during his preparation for his first Olympic Games, Tim's intermittent tendency to use of the second person pronoun distanced his current self from his past experiences and was indicative of an avoidance of reminders of the stressors. This linguistic strategy created a distance from the authorizing subject of the first person with access to subjective experience: “you [emphasis added] don't think to question it because you've [emphasis added] never been to the Olympics before, because you [emphasis added] don’t know what's required of an Olympic athlete”.

Even when the swimmers had acknowledged the enormity or the impact of the adversities to themselves there was a reluctance to disclose these experiences to others. Tim explained that a lack of maturity and confidence meant that he was unable to disclose his perceived injustice in response to organizational stressors. To identify the positive aspect of this experience he created a counternarrative of how he could have dealt with the experience:

I would have gone to the person at the top of the tree and . . . said, 'I'm not going to do what you want me to do, because you don't know me, you don't know the way I need to perform and what I need to do to train'. And I know that now.

The reflections on failure to disclose or speak out was paralleled in Jon's experience of a catastrophic swim following an ill-advised attempt at motivational encouragement from an influential member of the organization prior his Olympic race. In contrast to his eloquence throughout the rest of the interview, we interpreted Jon's use of profanity as evidence of his continued depth of emotion and unresolved issues:

I knew I was already fucked and I was like, 'Oh my God'. And I finished the race and it was a poor swim and a poor time. I was devastated. I never said to anybody at the time; I never even told my coach this is what [he] said to me.

Kate recounted not having the confidence to speak out about her deteriorating coach-athlete relationship. Instead of confronting her perception of her coach's lack of support, she adopted an avoidance coping strategy which involved leaving her coach in favor of another with a different coaching philosophy. However, she perceived the composite experience of coach-athlete conflict and avoidance coping as a positive experience: “[It] was probably the hardest year for me ... that was really tough. I have definitely learned a lot from that”. In recalling her relationship with a 
385

controlling boyfriend who exhibited little support for her Olympic aspirations, Zoe identified keeping her feelings to herself resulting in her having to cope with the experience alone: “sometimes I cried . . . I didn't like to express what was going on. So, most of the time I just kept it to myself and I just got through it somehow. But it was hard”. Denial as a defensive mechanism circumvented any cognitive processing of the event and delayed any constructive growth-related experiences. However, after a period of denial, the swimmers typically acknowledged the traumatic aspects of their adversities and progressed towards a conscious need to seek meaning in their experiences.

\section{Swimmers’ Experiences of Illusory Growth}

Apparent in all of the swimmers' descriptions of their experiences were self-deceptive or illusory perceptions of growth. Following the use of denial, the swimmers sought meaning in their experiences through the use of cognitive manipulations and the derogation of adversity-related experiences. In a number of instances, the adversities were perceived to have been resolved despite a paucity of evidence of change at either a cognitive or a behavioral level; we interpreted this as indicative of illusory growth. This extract illustrates how, following a probe from the interviewer, Zoe was unable to articulate what she meant and understood when she claimed positive life changes following a period of adversity:

Interviewer: What do you mean when you say that you "grew as a person”? Zoe: Um . . . I don’t know. It’s hard to explain. ... I didn’t have my parents, I had to rely on myself. Experiences were completely different; you know, the culture. People are completely different out there [in a foreign country] than they are here [in home country]. Their sense of humor and things like that. Just having to figure things out for myself . . . Seeking meaning. In response to intrusive ruminations, the swimmers began to acknowledge the distressing nature of their adversities. Zoe attempted to make sense of her adversities which was evidenced by multiple examples of questioning throughout her interview. Often, however, she was seeking meaning and answers that were not forthcoming; consequently, she shifted her search for an explanation from her own internal ruminations to direct questioning of the interviewer: "I was just thinking ... what else can I do? I had had this dream vision of 
413 getting a medal and then, all the hard work, I can't work any harder. Like what else could I have

414 done?” Kate also questioned her poor performance although, similar to Tim, her use of the

415 second person pronoun in the interview suggested an attempt to distance herself from the

416 distressing memories and any intrusive ruminations about her performances: "and you [emphasis

417 added] go to it [a major competition] and you [emphasis added] don't swim very well and it goes

418 through your [emphasis added] mind, 'why has that happened?’” Following his Olympic Games

419 experience, which was characterized by over-training and questionable decision-making by the

420 performance management team, Jon searched for answers surrounding some aspects of the

421 experience. This search for meaning included focusing on the ill-effects of an energy drink

422 provided for the swimmers at an Olympic holding camp: "I’ve looked into it after the fact and ...

423 a controversial substance was in this sports drink and [that] if exposed to sunlight for long periods

424 can have negative effects”. Although it appears that Jon found an explanation for his illness at the

425 camp, the search has resulted in no more than the comprehension of the experience. In explaining

426 his poor swim at the Olympic Games, Jon questioned the intentions of the individual who

427 provided him with poor advice: "I think with hindsight 'God damn it . . . what were you thinking,

428 why did you say that?’ . . . it definitely had an impact on that race”. In this latter instance, and

429 from details provided throughout the interview, it is apparent that in respect of this particular

430 adversity the search for meaning in the organizational stressors he experienced continues for Jon.

431 Cognitive manipulations. In an attempt to regain some semblance of normality, two of

432 the swimmers, Zoe who was still competing and Kate who had recently retired at the time of the

433 data collection, manipulated their thoughts and interpretations which involved the assimilation of

434 a positive bias and the development of a positive outlook. There was some evidence that Jon and

435 Tim also engaged in such cognitive manipulations and motivated illusions, but not to the same

436 extent.

We interpreted that Zoe and Kate assimilated their adversities into preexisting schema,

438 typically in a positively biased way to protect their identities as their sense of control and self-

439 esteem came under threat. Zoe's perceptions of her lack of control over her own life and her self-

440 esteem were negatively affected during her experience of living and training abroad. She 
441 described this period, during which she was over-trained and suffered depressive symptoms, as

442 one when she felt “lost. I felt lost. I didn't know what I was going to do”. Yet, in contradiction,

443 she reported what we interpreted as distorted positive perceptions of the experience and self-

444 deception indicating assimilation rather than accommodation:

445 Competitive swimming over there [in America] is different and that was the good part.

446 And I grew as a person. But my swimming was getting worse and worse ... [but] ... I

447 can honestly say that if I hadn't have gone [there] I would probably have stopped.

448 Identification of growing as a person is incongruent with the description of her experiences as her

449 swimming performance was in decline. Moreover, her use of "probably" and "honestly" in her

450 quote further indicates the uncertainty that she felt about being abroad. We interpreted that her

451 defensive distortion of the benefits of living abroad may have been driving her perceptions of

452 growth. In order to protect her identity as a world-class swimmer, she attempted to re-establish

453 that identity by moving back to her home country. This was characteristic of her behavior; when

454 her identity was threatened, Zoe made "fresh starts” which restored her perceptions of personal

455 control and stimulated (unrealistic) optimism and hope for the future: "I got a bronze medal at

456 Commonwealth Games . . . but I could have done a lot better than I did. After that I decided to

457 come home and ... have a better chance of qualifying for the Olympics”.

458 Kate assimilated a positive bias in her reflections on having to retire as a result of her

459 illness which had threatened her identity as a world-class athlete. She explained how "just"

460 qualifying for the national team following her previous successes was a major shock to her beliefs

461 about her identity and performance capabilities: "I'd made the Olympics final and got an Olympic

462 medal. I've broken world records. I've medaled at every major championship. . . . I went to

463 Commonwealth trials ... only just to make the team, which was a massive shock. So, the only

464 reason that I did carry on was because the [2012] Olympics were in London, to swim at the home

465 Games”. Eventually time allowed Kate to prepare for the transition to retirement and to assimilate

466 that knowledge in a positive way which gave her the illusion of having control and maintaining

467 her fragile self-esteem: "I had known . . . it was going to be my last meet, and I prepared myself

468 for it. It was sad to leave it all behind but ... I was ready to do something different”. 
The swimmers explicitly presented a positive outlook in terms of both their hopes for the

470 future and in their manipulation of their environments; we interpreted that this was particularly

471 the case for Zoe, who was still competing at the time of the data collection and, as a consequence,

472 was vulnerable to future disappointment in the performance domain. She explained that in the

473 future she hoped to be: "enjoying myself and I have these goals for the next 3 years and putting

$474100 \%$ into that . . . being happy with myself and giving it my best shot”. In an attempt to buffer

475 the impact of the adversities and possibly protect themselves from future setbacks, the swimmers

476 attempted to create a positive environment in which they could restore the positive assessments of

477 self, perceptions of personal control, and optimism for the future. Kate explained that she: "take[s]

478 the positives out of everything. . . I never surround myself by negative people, I always surround

479 myself with positive people”. On reflection, Tim recognized his unrealistic optimism following an

480 adversity but rationalized his belief in the context of the elite environment: "As an elite athlete

481 your primary instinct is to compete at that level and believe instinctively that you can achieve

482 what you want to achieve. If you don't then there's no point in doing it. . . [Following a serious

483 injury] I'd convinced myself that, despite my lack of fitness and health, I was still going to win.

484 Now, thinking back, that's illogical ...” Jon had similar reflections about his response to his

485 illness which comprised the retention of a positive outlook despite evidence to the contrary: "I

486 was holding onto the dream of still making the [2000] Olympics [in Sydney] ... when in actual

487 fact I probably shouldn't have”. The latter two quotes highlight the unrealistic optimism that is

488 characteristic of illusory growth that Jon and Tim experienced in the aftermath of their adversities.

489 However, the quotes also serve to illustrate enlightened retrospection that both swimmers were

490 able to undergo following a period of time.

491 Derogation of adversity-related experiences. In addition to the cognitive manipulations,

492 the swimmers also belittled their situation and attributes to maintain their self-esteem. They did

493 this, firstly, by comparing their situation to others who they perceived as worse off than them and,

494 secondly, by comparing their current attributes about the adversity to those they made in the past.

495 We interpreted these social and temporal comparison strategies as comprising illusions that

496 involved derogation of adversity-related experiences. In making sense of their experiences, 
497

498

499

500

501

502

503

504

505

506

507

508

509

510

511

512

513

514

515

516

517

518

519

520

521

522

523

524

several of the swimmers engaged in social comparison with others and identified that in comparison to others' experiences their experiences were not that traumatic. We interpreted that this allowed the swimmers to bolster, or at least maintain, their self-esteem. In reflecting on her performance slumps, Kate compared her experiences with other undefined individuals: "it's the worst feeling ever and you think at the time that it's the end of the world. I now look back and think, 'well it wasn't so bad - worse things in life can happen than not compete very well'”. She reflected on the opportunity to do charity work in Africa and how it allowed her to put her performance slumps into perspective: "there are so many other things in life [than swimming], I think I've realized that what could have happened, could have been so much worse. You don't realize it at the time”.

On occasions the swimmers' perceptions of growth were attributable to temporal aspects and the depreciation of the impact of their negative experiences giving the illusion of positive change. When Zoe was asked about the amusement that she displayed, inferred by laughter, when describing her reaction to a significant injury some years previously, she claimed that her initial negative emotions were "silly". She explained that although at the time the consequences of the injury were devastating for her, it did not adversely impact on her swimming career and, therefore, its relevance in respect of her identity and beliefs about her current self were diminished: "I’m trying to remember looking back how upset I was. Obviously I didn’t know what was to come and now I know that it was silly getting upset about it; it wasn’t a big deal”. This strategy was repeated in looking back on a controlling relationship, yet on this occasion not only did she explicitly identify that her response to experience was inappropriate but also that it had positive outcomes: "I was under the love spell where you don't realize what's going on. I think now it was so silly, but I think you have to go through these things and these phases. I think it probably made me stronger”. Kate engaged in temporal comparison with her current self to counter the extreme emotion associated with retirement that she had described as "harder than I ever thought it would be [but] it was an exciting change because, you know, I'd never experienced it before, and, you know, you really realize that swimming wasn't that hard!”

\section{Acceptance of Adversity}


After denial and self-deception, the swimmers began to disclose aspects of their adversities and seek support from the people around them. This social support came from three distinct sources: a sport psychologist, family members, and coaches. Three of the participants confided in an individual with sport psychology expertise to help them to negotiate their adversities. Tim reflected on his continuing engagement with a sport psychologist: "I’m still in touch with this person today, very, very sporadically. They reached out ... and we went through a process and came out the other side” and Zoe explained that she has remained in contact with a sport psychologist for nine years: "I speak to him quite a lot”. Jon recalled that when he spoke to a sport psychologist outside of his social network following his life threatening illness it allowed him to deal with the experience. The absence of emotional attachment gave Jon the opportunity to disclose:

There was going to be no ramifications socially to telling this psychologist how I was thinking and feeling. It allowed me to actually open up, pretty much cry. ... And as soon as she said, ‘you’ve been through something terrible,' it dawned on me that I had.

For Jon, his relationship with this individual was significant and had implications both in respect of his enhanced performance and his psychological wellbeing: weren’t for the significant changes I made and significant learnings and growth that I the adversities that they experienced, but also in the knowledge that family would be there for them if and when they were needed. Tim described the level of support that his parents provided:

547 "I owe absolutely everything ... to what my parents did. Unquestionable, often illogical, 548 ridiculous amounts of support coming ... from them”. Zoe explained that: "I talk to people I am 549 close with ... who understand, and we do things away from swimming”. Kate stated that: "I've got a great family that have always supported me”. 
553

554

555

556

557

558

559

560

561

562

563

564

565

566

567

568

569

570

571

572

573

574

575

576

577

578

579

580

cat and dog. ... Any disagreement there was was purely performance related or training related ... I had a very, very strong relationship [with him], but it is very hard to define”. He went on to explain: "If I ever got into serious trouble, for whatever reason it was, whether it was financial or whether I needed help with someone, he'd be the first person I'd pick up the phone to.” The linguistic strategies employed in this description of his relationship with his coach are interesting; the implication being that the coach-athlete relationship is strong and supportive, yet the tense used is future, suggesting that the opportunity for support is still there if required or, alternatively, that the opportunity for support was there but that it was not acted upon.

\section{Swimmers’ Experiences of Constructive Growth}

Apparent in some of the swimmers' descriptions of their experiences were constructive perceptions of growth. Despite experiencing enduring distress, Jon and Tim, whose retirements from competitive swimming were in 2004 and 2008 respectively, found meaning in their experiences, engaged in more meaningful cognitive processing, experienced a change in life philosophy, and exhibited behavioral actions indicative of constructive growth. For Kate, who retired in 2012, the analysis revealed some aspects of constructive growth, while Zoe, who was still competing at the time of data collection, provided the least evidence to support this superordinate theme. Hence, it appears that the passing of time and possibly retirement from sport, and associated distancing from events and broadening of experiences, can facilitate the realization of constructive growth.

Enduring distress. Distress was evident in all of the swimmers' accounts of their experiences. For example, after a disappointment at the World Championships, Zoe experienced considerable anguish: “I got really depressed, I couldn’t sleep and was crying a lot”. However, what distinguished constructive growth from illusory growth in the swimmers was the ongoing nature of this distress. More specifically, the absence of distress was interpreted as a selfdeceptive optimistic bias whereas the enduring presence of distress was interpreted as a form of acknowledging the adversity and the impact it had. Constructive growth involves making genuine changes as part of a disruptive and distressing process. Tim and Jon, in particular, experienced ongoing and enduring distress, although both swimmers acknowledged that there were periods of 
581

582

583

584

585

586

587

588

589

590

591

592

593

594

595

596

597

598

599

600

601

602

603

604

605

606

607

608

relief. Tim used metaphors such as a 'rollercoaster' and annotations on his timeline to explain his journey from adversity to growth:

It was a hellish slog that was blood, sweat, guts, tears. ... the road to the Olympics had some of the highest highs and lowest lows and, in short, was an emotional rollercoaster one which caused considerable anguish and heightened emotions.

In contrast to the eloquence used to articulate his experiences of injury and illness, the enduring distress that Jon experienced as a result of organizational stressors was apparent in his use of the profane when he described the interference of a performance director in his race preparation: "I was fucking so pissed off with hindsight about that. It was the wrong choice for [him] to step in and say that to me, literally minutes before my race”.

Finding meaning. Although seeking the meaning of the adversities was apparent in all of the swimmers, constructive growth was identifiable when the swimmers were able to progress to finding meaning, a process that often takes time. Tim acknowledged that the process of finding meaning in his back injury and the organizational stressors that he had experienced was unpleasant and took time: “[It] was a horrible process, a very slow process as well”. Jon stressed the importance of identifying the right time to address the emotional aspects of his illness, and that it was important for him to resolve the physical aspects of his illness first. The focus on the physical allowed Jon the opportunity to postpone addressing the fundamental threats to his identity and wellbeing: "I think I had to be physically better before I could . . . stop and think about it, 'what have you just been through?'” The focus of this process went beyond the comprehensibility of the adversities to appreciating the significance of an event in the swimmers' lives. For Jon, it was engagement with his sport psychologist that allowed him to acknowledge and make sense of what had happened:

For the clavicle fracture, [working with a sport psychologist] was about removing the gremlins that were blocking me from full, relaxed, optimal, sports performance. . . . From a psychological perspective, the illness recovery was more about ... emotional cleansing and psychological cleansing: ‘God I’ve been through something ridiculous here, something enormous'. I just needed to acknowledge that to myself with someone before I 
could move on.

Cognitive processing. The two male swimmers cognitively processed their experiences

611 involving a change to their identities and the positive accommodation of their adversities (as

612 opposed to assimilation into preexisting schema). This involved a more fundamental

613 transformation in the swimmers than the cognitive manipulations and motivated illusions

614 associated with illusory aspects of growth. Jon acknowledged a number of identity changes that

615 were evidenced through recognition of his different selves: "I picture my relationship with my

616 past self, my Olympic self, and the Olympics as sort of like a mentoring voice that questions you

617 at the same time”. Tim identified that as an outcome of his adversities he experienced a change in

618 how he approached life: "I've become a more pragmatic person, rather than somebody who is

619 emotional and maybe a bit of a romantic about the sport and didn’t temper that with just level-

620 headedness”.

621 Descriptions that referred to events that suggested a shattering and reforming of schema

622 were interpreted as indicative of positive accommodation. Jon described a restructuring of his

623 beliefs about his illness and his first clavicle injury. He described the depth of mental processing

624 and reflective pondering that he engaged in with his sport psychologist, which not only allowed

625 him to focus on the active mastery of his skills but also his perceptions of growth:

It was a sense of starting again, [but] it wasn’t a sense of 'right everything's fine now'; it was a ... moment of feeling cleansed ... being re-born. And then it was about re-growth. I still had to go back to my training . . . and start again to become better as a swimmer. . . . but the tools that [the psychologist] had given me ... [to] break it down physically, mentally, and technically ... allow[ed] me to grow. Philosophical change. Philosophical change involved a greater appreciation of life, a change in perspective, increased spirituality, and enhanced relationships. In discussing his lifethreatening illness which resulted in non-qualification for the 2000 Olympic Games, Jon explained: “I’m really glad that I was close to death because it’s made me appreciate my life so 
I suddenly valued what it was that I had, more than I had before, and it’s perhaps not until someone has taken something from you or threatened to take it from you ... that it gets magnified how much you want it and it gets focused.

Following retirement, Jon no longer had to conform to the performance narrative and this allowed him to appreciate the luxuries that he sacrificed as a result of his swimming career: "I like that I can now have a glass of wine and a nice meal and not worry about the calorific damage to my sports performance. ... I used to have to sacrifice that”. Tim explained a change in perspective following adversity:

I then had a mentality shift in my whole career. ... When you have a performance or an injury that knocks you for six. ... Your mentality needs to take on a slightly different tangent, in that it needs to become more logical.

Of the participants, only Jon explicitly identified an increase in spirituality but his description was significant in that it indicated a fundamental philosophical change. He referred to the illness experience as a "rebirth" which we interpreted as being integral to his growth experience. He further stated: “an openness to be spiritual has always sort of been with me, but it was definitely greater after this. I think that near death experience and the re-born, or re-birthing experience, heightened it”. The swimmers identified enhanced relationships as a result of their adversities but this only came after a period of time when they had had the opportunity to reflect on their past experiences. For Jon, spirituality was demonstrated in the way he now perceives his family: "I find the spiritual lifeline in nature, in the world, in my own existence in life, and in friends and family”. Kate explained that: "it wasn't until I retired that [I] realized . . . that there is more to life than . . . being a swimmer, and your family . . . are the most important people in your life”. In discussing his performance slumps, Tim identified that it was then, "that family bonds become strongest”.

Behavioral actions. There was some evidence of the swimmers’ behaviors and actions changing as a result of their adversities and involved them speaking out and engaging in philanthropic work. Although the initial response to adversity was a reticence to disclose, following cognitive processing and the enlistment of social support, the swimmers recognized 
665 that concealment of their adversities was not an adaptive strategy and they could articulate their

666 thoughts. Kate explained: "I definitely learned ... that I could speak my mind a lot more. ...

667 because I found that if you let things fester, it gradually gets worse and worse and worse”. She

668 interpreted that her charity work in Africa was only possible because she had retired and that

669 engagement in philanthropic work was a necessary part of her growth experiences. We further

670 interpreted that this demonstrated her openness to new experiences: "I’ve never felt like I did

671 when I was out there. . . . It was once-in-a-lifetime opportunity. . . . It does make you feel better

672 about yourself that you give something back”. Jon reflected on a desire to give something back to

673 swimming and explained the work that that his aquatic business has engaged in to improve the

674 lives of future generations: "If I were to advise youngsters . . . helping people improve and get

675 better, for me it's how you can have a happier sporting life, aside from a better performance

676 sporting life”.

677

Discussion

678

Using IPA of interviews and timelines, we extended Howells and Fletcher’s (2015) study

of adversarial growth in Olympic swimmers by exploring experiences of constructive and illusory

680

growth. Consistent with the findings of previous research in elite sport (e.g., Howells \& Fletcher,

681

2015, Sarkar et al., in press; Tamminen et al., 2013), we found perceived positive consequences

682 of adversarial-related experiences; however, in contrast to this research, we found that some of

683 these positive outcomes were indicative of illusory aspects of growth whereas others were more indicative of constructive growth. This finding is consistent with theoretical (cf. Maercker \& Zoellner, 2004; Zoellner \& Maercker, 2006a) and empirical (e.g., McFarland \& Alvaro, 2000; Sumalla, Ochoa, \& Blanco, 2009) advances in the broader psychology and trauma literature. The identification of both illusory and constructive growth in this study does not imply that reports of growth are mutually exclusive, rather that aspects of both may temporally fluctuate or even coexist. In line with the proposals of the Janus-faced model of self-perceived PTG (Maercker \& Zoellner, 2004; Zoellner \& Maercker, 2006a), our findings suggest that the earlier phases of the growth process were characterized by more illusory aspects of growth and fewer constructive aspects of growth in all of the swimmers. As time passed, two of the swimmers (who had retired 
693 some time prior to the interviews) displayed more constructive and fewer illusory aspects, whilst

694 the other two swimmers (one of whom had recently retired and the other who was still competing

695 at the time of the interview) continued to display more indicators of illusory growth. This finding

696 in part supports Zoellner and Maercker’s (2006b) observation that “with growing coping success,

697 the illusory side loses importance over time and the constructive side gains impact over time” (p.

698 349). Interestingly, it appears that retirement may play an important role in the evolution of

699 growth experiences due to the associated distancing from events and broadening of experiences

700 which may facilitate constructive growth (cf. Coakley, 1983).

701

As noted above, illusory and constructive growth both involve perceived positive consequences of adversarial-related experiences. Prior to growth occurring, however, all of the participants used denial as a short-term palliative coping strategy. This adaptive aspect of denial is important to highlight because denial is often reported as a maladaptive response to stressful events (Ivarsson, Johnson, \& Podlog, 2013; Wadsworth, 2015). However, in line with Maercker and Zoellner's (2004; Zoellner \& Maercker, 2006a) theorizing, denial if accompanied by deliberate thinking about the trauma and active coping efforts may serve a palliative function. Following denial, our findings suggest that different aspects or indicators of growth became apparent, suggesting that growth is multidimensional in nature (cf. Morris et al., 2005). It also appears that that temporality is significant in that those who exhibit constructive growth experience some aspects of illusory growth in the past. questions akin to “why me?” and "why did it happen?” The purpose of these deliberate reflections is to comprehend and understand why an event occurred. This finding supports tenets of several of the growth-related models and theories that the search for meaning is part of the growth process (Tedeschi \& Calhoun, 1995; Joseph \& Linley, 2005) but our findings suggest that if this search (regardless of outcome) focuses solely on comprehension (rather than significance) then the growth remains illusory (cf. Park, 2010). Other aspects characteristic of illusory growth were cognitive manipulations and the derogation of adversity-related experiences. Throughout the experience of illusory growth the swimmers used palliative coping strategies that were typically 
721

722

723

724

725

726

727

728

729

730

731

732

733

734

735

736

737

738

739

740

741

742

743

744

emotion-focused in nature. These strategies have been referred to in the growth literature as selfenhancement cognitions (Maercker \& Zoellner, 2004) and were employed by the swimmers to reduce distress and to defend or maintain aspects of their identities. The swimmers' use of optimistic language about some aspects of their experiences is consistent with Zoellner et al.'s (2008) finding that optimism is often a proxy for illusory growth. Regardless of how realistic this optimism was, illusory growth was also characterized by unconvincing claims to have grown that were not accompanied by consistency of accounts and evidence of transformational change. It has been argued that such claims represent defensive distortions (Wortman, 2004) in an attempt to defend an identity (Sumalla et al., 2009), as opposed to identity transformation. Although selfdeception has the potential to have a deleterious impact on an individual, we are not suggesting that illusory growth is negative per se. Rather illusions and self-deceptions can (and do) serve a positive psychological and performance development function (cf. Alicke \& Sedikides, 2009; Taylor, 1983). Indeed, several decades ago, Taylor (1983) discussed "illusion as essential to normal cognitive functioning" (p. 1167) and concluded that "the effective individual in the face of threat, then, seems to be one who permits the development of illusions, nurtures those illusions, and is ultimately restored by those illusions” (p. 1168).

Constructive growth was characterized by veridical transformational changes in the swimmers' lives that went beyond motivated illusions, wishful thinking, and defensive distortions. One aspect of constructive growth was the swimmers' enduring distress. Although it may appear counterintuitive to suggest that ongoing anguish is indicative of transformational change, our findings suggest that enduring distress represents an acknowledgement of the adversity and the impact it had, as opposed to an absence of distress which represents a selfdeceptive optimistic bias characteristic of illusory growth (cf. Taku, Calhoun, Cann, \& Tedeschi, 2008; Tedeschi \& Calhoun, 2004). Although denial was an initial response to adversity, it was the disclosure of adversity-related experiences and the seeking of social support that was a facilitator of constructive growth (cf. Prati \& Pietrantoni, 2009; Tamminen et al., 2013). Although meaning and comprehension were often sought as part of the growth process (as an aspect of illusory growth e.g., Jon's failure to find meaning in his organizational stressors), it was the finding of 
749

750

751

752

753

754

755

756

757

758

759

760

761

762

763

764

765

766

767

768

769

770

771

772

773

774

775

776

meaning and appreciation of the significance of an event that was indicative of constructive growth (cf. Day, 2013; Park, 2010) for example, Jon’s appreciation of the significance of his near death experience on his life. However, perhaps the main differentiators between illusory and constructive growth were the manipulation versus the processing of cognitions, and the associated integration into a preexisting schema (i.e., assimilation) versus the shattered and reformation of schema (i.e., accommodation) (cf. Howells \& Fletcher, 2015; Payne, Joseph, \& Tudway, 2007). Further, in addition to various indices of philosophical change (Galli \& Reel, 2012a; Tedeschi \& Calhoun, 1996), we also found that meaningful behaviors and actions appear to distinguish between illusory and constructive growth (cf. Hobfoll et al., 2007; Shakespeare-Finch \& Barrington, 2012).

In their critical evaluation of the use of IPA in psychology research, Brocki and Wearden (2006) highlighted the importance of acknowledging the limits of the representational nature of the data. A limiting aspect of the data in our study is that it is restricted to retrospective selfreports of growth that may conform to a cultural script present in elite swimming; that is, exaggerated expressions of positive behaviors in response to adversity. To partially circumvent this issue and to strengthen assertions of illusory growth, growth researchers should consider obtaining corroboratory evidence from social networks (Wortman, 2004), such as family, friends, partners, coaches (see, e.g., Wadey et al., 2013), and support staff, who may be in a position to provide further insight into adversarial growth. Furthermore, during the interviews for this study, several of the participants alluded to the impact that their experiences had on significant others. With the exception of Day and colleagues' studies of the impact of witnessing a traumatic injury of an athlete (Day, Bond, \& Smith, 2013; Day \& Schubert, 2012), there is no research exploring vicarious growth (Linley et al., 2003) in the sport domain. Regardless of the specific research question investigated, sport psychology researchers should consider multidimensional and temporal aspects of both constructive and illusory growth (cf. Morris et al., 2005), together with using other research methods such as case study analysis (see, e.g., Vilenica, Shakespeare-Finch, \& Obst, 2013) and quantitative inventories and surveys (see, e.g., Tedeschi \& Calhoun, 1996). Although many questions remain, the study of adversarial growth in elite sport is gaining 
777 momentum and the emerging findings have important theoretical and practical implications for 778 the field of sport psychology.

779 
Alicke, M. D., \& Sedikides, C. (2009). Self-enhancement and self-protection: What they are and what they do. European Review of Social Psychology, 20(1), 1-48. doi: $10.1080 / 10463280802613866$

Best, M., Streisand, R., Catania, L., \& Kazak, A. E. (2001). Parental distress during pediatric 785 leukemia and posttraumatic stress symptoms (PTSS) after treatment ends. Journal of Pediatric Psychology, 26(5), 299-307. doi:10.1093/jpepsy/26.5.299

Brewer, B. W. (1993). Self-identity and specific vulnerability to depressed mood. Journal of 788 Personality, 61(3), 343-364. doi:10.1111/1467-6494.ep9402021311

Brewer, B. W., Van Raalte, J., \& Linder, D. E. (1993). Athletic identity: Hercules’ muscles or Achilles’ heel. International Journal of Sport Psychology, 24. 237-254.

Brocki, J. M., \& Wearden, A. J. (2006). A critical evaluation of the use of interpretative

Calhoun, L. G., Cann, A., \& Tedeschi, R. G. (2010). The posttraumatic growth model: phenomenological analysis (IPA) in health psychology. Psychology \& Health, 21(1), 87Sociocultural considerations. In T. Weiss \& R. Berger (Eds.), Posttraumatic growth and culturally competent practice: Lessons learned from around the globe (pp. 1-14). Hoboken, NJ: Wiley Online Library. doi: 10.1002/9781118270028.ch1

Calhoun, L. G., \& Tedeschi, R. G. (1998). Posttraumatic growth: Future directions. In R. G. Tedeschi, C. L. Park, \& L. G. Calhoun (Eds.), Posttraumatic growth: Theory and research

Caron, J., Bloom, G., Johnston, K., \& Sabiston, C. (2013). Effects of multiple concussions on retired national hockey league players. Journal of Sport and Exercise Psychology, 35, 168179.

Coakley, J. J. (1983). Leaving competitive sport: Retirement or rebirth? Quest, 35(1), 1-11. 
Crawford, J. J., Gayman, A. M., \& Tracey, J. (2014). An examination of post-traumatic growth in Canadian and American ParaSport athletes with acquired spinal cord injury. Psychology of Sport and Exercise, 15(4), 399-406. doi:10.1016/j.psychsport.2014.03.008

811 Creswell, J. W. (2009). Research design: Qualitative, quantitative, and mixed methods approaches.

812 Thousand Oaks, CA: Sage.

813 Creswell, J. W., \& Miller, D. L. (2000). Determining validity in qualitative inquiry. Theory into 814 practice, 39(3), 124-130. doi: 10.1207/s15430421tip3903_2

815 Curtin, M., \& Fossey, E. (2007). Appraising the trustworthiness of qualitative studies: Guidelines for 816 occupational therapists. Australian Occupational Therapy Journal, 54(2), 88-94. doi:

818 Day, M. C. (2013). The role of initial physical activity experiences in promoting posttraumatic growth in Paralympic athletes with an acquired disability. Disability \& Rehabilitation, 35(24), 2064-2072. doi:10.3109/09638288.2013.805822

Day, M. C., Bond, K., \& Smith, B. (2013). Holding it together: Coping with vicarious trauma in sport. Psychology of Sport and Exercise, 14(1), 1-11. doi:10.1016/j.psychsport.2012.06.001

Day, M. C., \& Schubert, N. (2012). The impact of witnessing athletic injury: A qualitative

Day, M. C., \& Wadey, R. (2016). Narratives of trauma, recovery, and growth: The complex role of sport following permanent acquired disability. Psychology of Sport and Exercise, 22, 131-138. doi: 10.1016/j.psychsport.2015.07.004

Douglas, K., \& Carless, D. (2006). Performance, discovery, and relational narratives among women professional tournament golfers. Women in Sport and Physical Activity Journal, 15(2), 14-27. for female athletes. Journal of Sexual Aggression, 8(2), 37-48. doi: 
835 Fletcher, D., Hanton, S., \& Mellalieu, S. D. (2006). An organizational stress review: conceptual and theoretical issues in competitive sport. In S. Hanton \& S. D. Mellalieu (Eds.), Literature reviews in sport psychology (pp. 321-373). Hauppauge, NY: Nova Science.

Galli, N., \& Reel, J. J. (2012a). 'It was hard, but it was good': A qualitative exploration of stressrelated growth in division I intercollegiate athletes. Qualitative Research in Sport, Exercise and Health, 4(3), 297-319. doi: 10.1080/2159676X.2012.693524

841

Galli, N., \& Reel, J. J. (2012b). Can good come from bad? An examination of adversarial growth in Division I NCAA athletes. Journal of Intercollegiate Sport, 5, 199-212.

Giddens, A. (1984). The constitution of society: Outline of the theory of structuration. Glasgow, UK: University of California Press.

Hassell, K., Sabiston, C. M., \& Bloom, G. A. (2010). Exploring the multiple dimensions of social support among elite female adolescent swimmers. International Journal of Sport Psychology, 41(4), 340-359.

Hobfoll, S., Hall, B., Canetti Nisim, D., Galea, S., Johnson, R., \& Palmieri, P. (2007). Refining our understanding of traumatic growth in the face of terrorism: Moving from meaning cognitions to doing what is meaningful. Applied Psychology, 56(3), 345-366. doi: 10.1111/j.1464-0597.2007.00292.x

Howells, K., \& Fletcher, D. (2015). Sink or swim: Adversity- and growth-related experiences in Olympic swimming champions. Psychology of Sport and Exercise, 16, 37-48. doi: 10.1016/j.psychsport.2014.08.004

Ivarsson, A., Johnson, U., \& Podlog, L. (2013). Psychological predictors of injury occurrence: A prospective investigation of professional Swedish soccer players. Journal of Sport Rehabilitation, 22(1), 19-26.

Janoff-Bulman, R. (1992). Shattered assumptions: Towards a new psychology of trauma. New York, NY: The Free Press. doi:10.1037/0033-295X.103.4.670

Joseph, S., \& Linley, A. (2005). Positive adjustment to threatening events: An organismic valuing theory of growth through adversity. Review of General Psychology, 9(3), 262-280. doi:10.1037/1089-2680.9.3.262 
863

864

865

866

867

868

Joseph, S., \& Linley, P. A. (2006). Growth following adversity: Theoretical perspectives and implications for clinical practice. Clinical Psychology Review, 26(8), 1041-1053. doi:10.1016/j.cpr.2005.12.006

Joseph, S., Murphy, D., \& Regel, S. (2012). An affective-cognitive processing model of posttraumatic growth. Clinical Psychology \& Psychotherapy, 19(4), 316-324. doi:

$$
\text { 10.1002/cpp.1798 }
$$

Kornbluh, M. (2015). Combatting challenges to establishing trustworthiness in qualitative research. Qualitative Research in Psychology,12(4), 397-414. doi: 10.1080/14780887.2015

Larkin, M., \& Thompson, A. (2012). Interpretative phenomenological analysis. In A. Thompson \& D. Harper (Eds). Qualitative research methods in mental health and psychotherapy: A guide for students and practitioners (pp. 99-116). Oxford, UK: John Wiley.

Larkin, M., Watts, S., \& Clifton, E. (2006). Giving voice and making sense in interpretative phenomenological analysis. Qualitative Research in Psychology, 3(2), 102-120

Lazarus, R. S. (1999). Stress and emotion: A new synthesis. London, UK: Free Association.

Lazarus, R. S. (1966). Psychological stress and the coping process. New York City, NY: McGraw-Hill.

Lechner, S. C., \& Antoni, M. H. (2004). Posttraumatic growth and group-based interventions for persons dealing with cancer: What have we learned so far? Psychological Inquiry, 15(1), 35-41.

Levy, A. R., Polman, R. C., Nicholls, A. R., \& Marchant, D. C. (2009). Sport injury rehabilitation adherence: Perspectives of recreational athletes. International Journal of Sport and Exercise Psychology, 7(2), 212-229.

Linley, P. A. (2003). Positive adaptation to trauma: Wisdom as both process and outcome. Journal of Traumatic Stress, 16(6), 601-610. doi: 10.1023/B:JOTS.0000004086.64509.09

Linley, P. A., \& Joseph, S. (2004). Positive change following trauma and adversity: A review. Journal of Traumatic Stress, 17(1), 11-21. doi: 0.1023/B:JOTS.0000014671.27856.7e

Linley, P. A., Joseph, S., Cooper, R., Harris, S., \& Meyer, C. (2003). Positive and negative changes following vicarious exposure to the September 11 terrorist attacks. Journal of 
891

892

Traumatic Stress, 16(5), 481-485. doi: 10.1023/A:1025710528209

Maercker, A., \& Zoellner, T. (2004). The Janus face of self-perceived growth: Toward a twocomponent model of posttraumatic growth. Psychological Inquiry, 15(1), 41-48.

McDonough, M. H., Sabiston, C. M., \& Ullrich-French, S. (2011). The development of social relationships, social support, and posttraumatic growth in a dragon boating team for breast cancer survivors. Journal of Sport and Exercise Psychology, 33(5), 627-648.

McFarland, C., \& Alvaro, C. (2000). The impact of motivation on temporal comparisons: Coping with traumatic events by perceiving personal growth. Journal of Personality and Social Psychology, 79(3), 327-343. doi:10.1037/0022-3514.79.3.327

Morris, B. A., Shakespeare-Finch, J., Rieck, M., \& Newbery, J. (2005). Multidimensional nature of posttraumatic growth in an Australian population. Journal of Traumatic Stress, 18(5), 575-585. doi: 10.1002/jts.20067

Mottier, V. (2005). The interpretive turn: history, memory, and storage in qualitative research. Forum Qualitative Sozialforschung (Forum: Qualitative Social Research), 6(2), Art. 33, http://nbn-resolving.de/urn:nbn:de:0114-fqs0502330.

Mummery, K. (2005). Essay: Depression in sport. The Lancet, 366(1), S36-S37. doi:

$$
\text { 10.1016/S0140-6736(05)67840-3 }
$$

Papathomas, A., \& Lavallee, D. (2010). Athlete experiences of disordered eating in sport. Qualitative Research in Sport and Exercise, 2(3), 354-370. doi: $10.1080 / 19398441.2010 .517042$

Park, C. L. (2004). The notion of growth following stressful life experiences: Problems and prospects. Psychological Inquiry, 69-76.

Park, C. L. (2010). Making sense of the meaning literature: An integrative review of meaning making and its effects on adjustment to stressful life events. Psychological Bulletin, 136(2), 257. doi: $10.1037 / \mathrm{a} 0018301$

Park, C., Cohen, L., \& Murch, R. (1996). Assessment and prediction of stress-related growth. Journal of Personality, 64(1), 71-105. doi: 10.1111/j.1467-6494.1996.tb00815.x

Payne, A. J., Joseph, S., \& Tudway, J. (2007). Assimilation and accommodation processes 
following traumatic experiences. Journal of Loss and Trauma, 12(1), 75-91. doi:10.1080/15325020600788206

Powell, J. W., \& Barber-Foss, K. D. (2000). Sex-related injury patterns among selected high school sports. The American Journal of Sports Medicine, 28(3), 385-391.

Prati, G., \& Pietrantoni, L. (2009). Optimism, social support, and coping strategies as factors contributing to posttraumatic growth: A meta-analysis. Journal of Loss and Trauma, 14(5), 364-388. doi: 10.1080/15325020902724271

Sabiston, C. M., McDonough, M. H., \& Crocker, P. R. (2007). Psychosocial experiences of breast cancer survivors involved in a dragon boat program: Exploring links to positive psychological growth. Journal of Sport and Exercise Psychology, 29(4), 419-438

Salim, J., Wadey, R., \& Diss, C. (2015). Examining the relationship between hardiness and perceived stress-related growth in a sport injury context. Psychology of Sport and Exercise. 19, 10-17. doi:10.1016/j.psychsport.2014.12.004

Salim, J., Wadey, R., \& Diss, C. (in press). Examining hardiness, coping and stress-related growth following sport injury. Journal of Applied Sport Psychology. doi: 10.1080/10413200.2015.1086448

Sarkar, M., \& Fletcher, D. (2014). Psychological resilience in sport performers: a review of stressors and protective factors. Journal of Sports Sciences, 32(15), 1419-1434. doi:10.1080/02640414.2014.901551

Sarkar, M., Fletcher, D., \& Brown, D. J. (in press). What doesn’t kill me...: Adversity-related experiences are vital in the development of superior Olympic performance. Journal of Science and Medicine in Sport. doi:10.1016/j.jsams.2014.06.010

Shakespeare-Finch, J., \& Barrington, A. J. (2012). Behavioural changes add validity to the construct of posttraumatic growth. Journal of Traumatic Stress, 4, 433-439. doi:10.1002/jts.21730

Sheridan, J., Chamberlain, K., \& Dupuis, A. (2011). Timelining: Visualizing experience. Qualitative Research, 11(5), 552-569. doi:10.1177/1468794111413235 
and its contribution to qualitative research in psychology. Qualitative Research in Psychology, 1(1), 39-54. doi: 10.1191/1478088704qp004oa

Smith, J. A. (2011). Evaluating the contribution of interpretative phenomenological analysis. Health Psychology Review, 5(1), 9-27. doi:10.1080/17437199.2010.510659

Smith, J. A., Flowers, P., \& Larkin, M. (2009). Interpretative phenomenological analysis: Theory, method and research. Thousand Oaks, CA: Sage.

Stirling, A., \& Kerr, G. (2008). Elite female swimmers' experiences of emotional abuse across time. Journal of Emotional Abuse, 7(4), 89-113. doi: 10.1300/J135v07n04_05

Sumalla, E. C., Ochoa, C., \& Blanco, I. (2009). Posttraumatic growth in cancer: Reality or illusion? Clinical Psychology Review, 29(1), 24-33. doi: 10.1016/j.cpr.2008.09.006

Taku, K., Calhoun, L. G., Cann, A., \& Tedeschi, R. G. (2008). The role of rumination in the coexistence of distress and posttraumatic growth among bereaved Japanese university students. Death Studies, 32(5), 428-444. doi: 10.1080/07481180801974745

Tamminen, K. A., Holt, N. L., \& Neely, K. C. (2013). Exploring adversity and the potential for growth among elite female athletes. Psychology of Sport and Exercise, 14(1), 28-36. doi: 10.1016/j.psychsport.2012.07.002

Taylor, S. E. (1983). Adjustment to threatening events: A theory of cognitive adaptation. American Psychologist, 38(11), 1161-1173. doi:10.1037/0003-066X.38.11.1161

Taylor, S. E., \& Armor, D. A. (1996). Positive illusions and coping with adversity. Journal of Personality, 64(4), 873-898. doi:10.1111/j.1467-6494.1996.tb00947.x

Taylor, S. E., Kemeny, M. E., Reed, G. M., Bower, J. E., \& Gruenewald, T. L. (2000). Psychological resources, positive illusions, and health. American Psychologist, 55(1), 99109. doi:10.1037/0003-066X.55.1.99

Tedeschi, R. G., \& Calhoun, L. G. (1995). Trauma \& transformation: Growing in the aftermath of suffering. Thousand Oaks, CA: Sage.

Tedeschi, R. G., \& Calhoun, L. G. (1996). The posttraumatic growth inventory: Measuring the positive legacy of trauma. Journal of Traumatic Stress, 9(3), 455-471. doi:10.10007/BF02103658 
975 Tedeschi, R. G., \& Calhoun, L. G. (2004). Posttraumatic growth: Conceptual foundations and empirical evidence. Psychological Inquiry, 15(1), 1-18. doi: 10.1207/s15327965pli1501_01

Vilenica, S., Shakespeare-Finch, J., \& Obst, P. (2013). Exploring the process of meaning making in healing and growth after childhood sexual assault: a case study approach. Counselling Psychology Quarterly, 26(1), 39-54. doi:10.1080/09515070.2012.728074

Wadey, R., Clark, S., Podlog, L., \& McCullough, D. (2013). Coaches' perceptions of athletes' stress-related growth following sport injury. Psychology of Sport and Exercise, 14(2), 125135. doi:10.1016/j.psychsport.2012.08.004

Wadey, R., Evans, L., Evans, K., \& Mitchell, I. (2011). Perceived benefits following sport injury: A qualitative examination of their antecedents and underlying mechanisms. Journal of 985 Applied Sport Psychology, 23(2), 142-158. doi:10.1080/10413200.2010.543119

Wadsworth, M. E. (2015). Development of maladaptive coping: A functional adaptation to chronic, uncontrollable stress. Child Development Perspectives, 9(2), 96-100. doi:10.1111/cdep.12112

Widows, M. R., Jacobsen, P. B., Booth-Jones, M., \& Fields, K. K. (2005). Predictors of 990 posttraumatic growth following bone marrow transplantation for cancer. Health Psychology, 24(3), 266-273. doi:10.1037/0278-6133.24.3.266

Willig, C. (2009). Introducing qualitative research in psychology (2nd ed.). Glasgow, UK: Open University Press.

Wortman, C. B. (2004). Posttraumatic growth: Progress and problems. Psychological Inquiry, 995 15(1), 81-90. Retrieved from http://www.jstor.org/stable/20447207

Zoellner, T., \& Maercker, A. (2006a). Posttraumatic growth in clinical psychology - A critical review and introduction of a two component model. Clinical Psychology Review, 26(5), 626-653. doi:10.1016/j.cpr.2006.01.008

Zoellner, T., \& Maercker, A. (2006b). Posttraumatic growth and psychotherapy. In L.G. Calhoun \& R.G. Tedeschi (Eds.), Handbook of posttraumatic growth (pp. 334-354). Mahwah, NJ:

1002 Zoellner, T., Rabe, S., Karl, A., \& Maercker, A. (2008). Posttraumatic growth in accident 

survivors: Openness and optimism as predictors of its constructive or illusory sides. Journal of Clinical Psychology, 64(3), 245-263. doi:10.1002/jclp.20441

1005 Zoellner, T., Rabe, S., Karl, A., \& Maercker, A. (2011). Post-traumatic growth as outcome of a 1006 cognitive-behavioural therapy trial for motor vehicle accident survivors with PTSD. Psychology and Psychotherapy: Theory, Research and Practice, 84(2), 201-213. doi: $10.1348 / 147608310 X 520157$ 